J Child Fam Stud. 2016 December ; 25(12): 3760-3770. doi:10.1007/s10826-016-0526-2.

\title{
Child Welfare Involved Parents and Pathways Triple P: Perceptions of Program Acceptability and Appropriateness
}

\author{
Ericka M. Lewis, Megan Feely, \\ University of Connecticut; West Hartford, Connecticut \\ Kristen D. Seay, \\ University of South Carolina; Columbia, South Carolina \\ Nicole Fedoravicis, and \\ Washington University in St. Louis; St. Louis, Missouri \\ Patricia L. Kohl \\ Washington University in St. Louis; St. Louis, Missouri
}

\begin{abstract}
Nearly half of children in the child welfare system have clinically significant behavior problems and are at risk of developing disruptive behavioral disorders. Yet, behavioral parent training interventions, which are the most effective way to treat these problems, are rarely provided to child welfare involved families. As a result, little is known about the acceptability and appropriateness of these parent training interventions with these families. This qualitative study explored implementation outcomes of an evidenced-based parenting intervention, Pathways Triple $\mathrm{P}$, with families in the child welfare system. Semi-structured interviews were conducted with parents investigated for child maltreatment $(n=47)$; following participation in the Pathways Triple P. Parents were asked about their perceptions of acceptability (program satisfaction) and appropriateness (program fit). Despite the complicated and often chaotic lives common among this vulnerable population, study findings suggest that most parents found the intervention to be useful and relevant. Pathways Triple P's content, structure and materials for parents were key aspects of acceptability and appropriateness. Barriers to participation were also identified separately for parents who did not receive the full dosage of the intervention. Study findings indicate that Pathways Triple $\mathrm{P}$ is a promising strategy to improve behavioral health outcomes for maltreated children and increase positive parenting behaviors for child welfare involved parents.
\end{abstract}

Corresponding Author's Note: E. Lewis, Washington University in St. Louis, One Brookings Drive, Campus Box 1196, St. Louis, Missouri 63130, Ericka@wustl.edu.

Disclosure of potential conflict of interest: The authors declare that they have no conflict of interest.

Research involving human participants: All procedures performed in studies involving human participants were in accordance with the ethical standards of the institutional and/or national research committee and with the 1964 Helsinki declaration and its later amendments or comparable ethical standards.

Informed consent: Informed consent was obtained from all individual participants included in the study. 


\section{Keywords}

child protective services; parenting programs; evidence-based interventions; implementation outcomes; Triple P

\section{Introduction}

It has been well documented that parental factors, such as parenting attitudes, stress, and child rearing practices have been associated with child developmental trajectories (Kessler, Chiu, Demler, \& Walters, 2005; Murray \& Farrington, 2010; Williams, Van Dorn, Bright, Jonson-Reid, \& Nebbitt, 2010). Parent mediated interventions, often referred to as behavioral parent training (BPT), are commonly utilized to treat child behavior problems through changes in parents' behaviors (Gershater-Molko, Lutzker, \& Wesch, 2003; Sanders, Markie-Dadds, \& Turner, 2003). BPT programs teach parents how to structure engaging activities and manage child misbehavior, which can increase positive parenting behaviors and parent-child interactions, and reduce risk factors related to child maltreatment (Ammerman, 1998; Gershater-Molko et al., 2003). BPT programs with demonstrated effectiveness, such as Positive Parenting Program (Triple P), provide parents with strategies to reduce child behavior problems (Turner \& Sanders, 2006) by incorporating elements of modeling (e.g., observing the behaviors of others), skill practice, and feedback (reinforcement of desired behavior). Further, child maltreatment researchers argue that a parent's participation in an evidence-based BPT program may reduce rates of maltreatment recidivism (Barth, 2009; Chaffin, Bonner, \& Hill, 2001; Chaffin, Hecht, Bard, Silovsky, \& Beasley, 2012; Lundahl, Tollefson, Risser, \& Lovejoy, 2008; Prinz, Sanders, Shapiro, Whitaker, \& Lutzker, 2009).

Triple $\mathrm{P}$ is a continuum of parenting programs of differing levels of intensity ranging from Levels 1 to 5 (see Sanders, Markie-Dadds, \& Turner, 2003 for a detailed description of each level). Level 4 Triple P is a BPT program and there is a considerable amount of evidence supporting its positive impact on child behavioral outcomes and parenting practices (Sanders \& Pidgeon, 2005). For example, Sanders, Markie-Dadds, Tully, and Bor (2000) examined the effects of Triple $\mathrm{P}$ on preschoolers at high risk of developing conduct problems and found that participation in Triple $\mathrm{P}$ was associated with lower levels of parent-reported disruptive child behaviors, compared to a wait list group. Similar results were reported in three meta-analyses of Triple P efficacy and effectiveness studies (Bodenmann, Cina, Ledermann, \& Sanders, 2008; De Graff, Speetjens, Smit, De Wolff, \& Tavecchio, 2008; Nowak \& Heinrichs, 2008). Overall, findings suggest that parents who participated in Triple $\mathrm{P}$ had more positive effects on parenting factors across multiple domains, including positive parent-child interactions and parenting efficacy than parents who did not receive Triple $\mathrm{P}$. Level 5 Triple P, commonly referred to as Pathways Triple P, was developed for parents of children at-risk for physical abuse and neglect. Pathways Triple P includes a combination of Level 4 and supplemental modules focused on anger management, parental attributions of their child's behavior, and strategies for coping with stress (Sanders \& Pidgeon, 2005). Research has shown that parents who received Pathways Triple P reported greater improvements in child and parent behaviors compared to those assigned to the control group 
(Wiggins, Sofronoff, \& Sanders, 2009). Despite the empirical support of Pathways' impact on child behavioral outcomes with various populations, to date, only one small pilot study has explored case level outcomes with families in the US child welfare system (Author, XXXX).

While EBIs are assumed to be appropriate for the majority of the population, researchers often fail to consider the context in which the participant functions and the implementation of programs in diverse settings. To guide the assessment of implementation, this study draws upon the Conceptual Model of Implementation Research (Proctor et al., 2009), which identifies key outcomes to assess the success of implementing EBIs in diverse settings. Client-level implementation outcomes include acceptability (e.g., parent's satisfaction with intervention components, delivery, and content) and appropriateness (e.g., parent's perception of program fit and relevance). According to the model, intervention effectiveness and client functioning are impacted by implementation outcomes (Proctor et al., 2009). Therefore, assessing implementation outcomes can provide insight on the suitability of Pathways for parents receiving services from the child welfare system. Additionally, gaining a better understanding of these outcomes can increase the uptake and adoption of EBIs in the public service sector, and ultimately decrease program dropout rates.

Little is known about the satisfaction with and appropriateness of Pathways with children in one of the highest risk groups for behavior problems - those involved in the child welfare system. Progress toward treatment goals is commonly examined to gauge intervention effectiveness. However, change in clinical outcomes is only one metric of success when examining the effectiveness of an EBI. An EBI can only truly be successful when those in need also display the following: 1) Satisfaction with program content and delivery, 2) Perception that the program is relevant to their needs, and 3) Active participation (Proctor et al., 2009; Proctor et al., 2011). The challenge of engaging high-risk families in evidencebased services has long plagued child maltreatment research. In fact, dropout rates are especially high in parenting programs in the child welfare system, with consistent reports of rates never falling below 30\% and reaching as high as 70\% (Chaffin et al., 2001; DePanfilis \& Dubowitz, 2005; Gershater-Molko et al., 2003; Hansen \& Warner, 1994; Lundquist \& Hansen, 1998). This may be due, in part, to parents' attitudes towards treatment, which has a direct impact on their commitment to treatment participation and intervention effectiveness (Kazdin \& Wassell, 2000; Kruzich, Jivanjee, Robinson, \& Friesen, 2014; Staudt, 2007).

Taken together the data highlight the need for more research on client-focused implementation outcomes of evidence-based programs within the child welfare system.

This study seeks to explore child welfare involved parents' perceptions of the relevance and fit of one EBI, Pathways Triple P, to their needs. Specifically, through semi-structured interviews, the early implementation outcomes acceptability and appropriateness were assessed. Findings from the study can build upon effectiveness research to make the case for large-scale adoption and uptake of BPT programs, such as Pathways, in child welfare settings. 


\section{Method}

\section{Participants}

Inclusion Criteria-This qualitative study included families in the treatment condition of a larger randomized controlled trial (RCT) who were receiving the Pathways Triple $\mathrm{P}$ intervention (citation omitted for blind review). The study was approved by the Institutional Review Board at [omitted for blind review]. Parents were referred to the program by their child welfare case manager, following a hotline report made to state and contract agencies in Missouri. Case managers obtained verbal permission to share their contact information with the study team. A study team member contacted potential participants within 2 business days of receiving their information from the children's services worker in order to confirm study eligibility and invite them to participate in the study. Consenting parents were then randomly assigned to Pathways Triple P or treatment as usual. Study inclusion criteria were: (1) be an African American or Caucasian parent; (2) be at least 18 years of age; (3) be able to speak English; and (4) have an open case with the state child welfare agency. Child inclusion criteria included the following: (1) be between the ages of 3 and 11; (2) live in the home with the parent; and (3) be medically healthy (e.g., no history of severe developmental delays). Only African American and Caucasian parents were recruited for this study because they are most representative of the population of child welfare involved families in this Midwestern city.

Sample-Seventy-five participants were randomly assigned to the Pathways treatment condition. Of those participants, 69 received the intervention (full intervention $n=32$; partial intervention $n=37$ ), and were eligible for the qualitative interview. Sixty-nine percent of all eligible parents participated in the qualitative interviews ( $n=47$ parents). These interviews were conducted with two types of parents: completers $(n=29)$ and non-completers $(n=18)$. Completers were defined as parents who participated in 13 or more sessions, and noncompleters included parents who received 12 or fewer sessions of the Pathways Triple P intervention. The session cut-off number was set at 13 sessions because early in the delivery of the intervention, it was determined that the content covered in week three (e.g., anger) should be divided into two weeks. Therefore, some parents received the intervention in its entirety at 13 sessions, and some at 14 sessions.

Among completers and non-completers, on average, parents were 31.9 years old, entirely female, and mostly African American (65\%). The majority of the sample struggled to pay bills each month (76\%) and almost all families were eligible for the Supplemental Nutrition Assistance Program. More than half of the caretakers were unemployed (60\%). Children ranged in age from 3 to 11 years old with a mean age of 7.04 years and about half were female (52\%). More than half the children (52\%) were in the clinical range on the Eyberg child behavior measure (Eyberg \& Ross, 1978), putting them at higher risk of developing a disruptive behavioral disorder.

\section{Procedure}

Data were collected through structured and semi-structured interviews. A structured interview, consisting of standardized measures assessing parenting behaviors, parental anger, 
stress, mental health, substance use, intimate partner violence, and child behavior problems, was administered to parents at baseline and at the completion or termination of the program. At post-test, semi-structured interviews were conducted with all treatment parents. The qualitative interviewers were trained and supervised by an experienced qualitative researcher, and the interviews were audio recorded and transcribed. All structured and semistructured interviews were conducted in the participant's home and lasted, on average, 60 minutes. Post-test data collection occurred following completion of the last session or after it was determined that the family would not be completing the intervention. Typically, posttests occurred within one week of the last session.

Intervention-This study used Pathways Triple P, which will be referred to as Pathways for the duration of the paper (Sanders \& Pidgeon, 2005). Pathways consisted of weekly sessions that were delivered in the parent's home. If home visits were not an option, the practitioners agreed to meet at another location convenient for the parent. Parents received a set of workbooks containing information and activities that reinforced the parenting skills and strategies introduced by the practitioner. Detailed information on the content covered throughout the program is displayed in Table 1 (Sanders \& Pidgeon, 2005). The practitioners also used Pathways videos to demonstrate desired parenting skills. Families completed an average of 11 sessions. The four practitioners who delivered the intervention were trained and accredited in Pathways. They received regular supervision throughout the intervention from experienced clinicians also trained in the intervention. Intervention sessions were audio recorded to assess treatment fidelity. The audio recordings were reviewed by the principal investigator and trained research assistants, and treatment fidelity was measured using a project-developed fidelity instrument. This instrument assessed the extent to which practitioners adhered to session agendas and activities outlined in the Triple P manual.

\section{Measures}

A semi-structured interview guide was developed to address the key domains of the research questions. The main topics covered along with sample questions are displayed in Table 2. The questions were refined throughout the first few interviews. Probes or follow-up questions were also included in the interview guide. As noted in Table 2, questions related to barriers to participation were only asked of those who did not complete the intervention (i.e., non-completers).

\section{Data Analyses}

Our analysis employed an ongoing examination between individual cases and comparison across cases. Following an approach outlined by Pope, Ziebland, \& Mays (2000), over multiple meetings, a team of six investigators read eight transcripts independently for a general sense of the acceptability of fit and appropriateness of the program. This also led to the development of a codebook. Upon agreement of the initial codebook, transcripts were coded for themes: parent-child relationships, parenting skills gained, program materials, and barriers to participation. Throughout this process, investigators discussed coded data and coding disagreements, and formed agreement on all coded segments. The framework method was also used to manage and analyze the qualitative data. Commonly used for thematic analysis of semi-structured interviews, the framework method (Ritchie \& Lewis, 2003) is a 
systematic process of categorizing qualitative data by creating matrices, containing quotations and text phrases, organized by theme (columns) and participant interviews (rows).

When considering the analysis process, the framework method allows for thematic comparisons across all cases and for the identification of patterns among participants who have similar experiences, and perceptions of the program. The process aided the research team's determination about whether there was sufficient evidence for the proposed themes. Two investigators developed a thematic matrix based on statement of texts from each transcript (Miles \& Huberman, 1994; Ritchie \& Lewis, 2003) to form a deeper understanding of the participants' perspectives. The matrix was reviewed by the research team several times in subsequent team meetings in order to draw consensus on emerging themes. NVivo 10 (2012) and Microsoft Excel 2013 were used to manage the data and analysis processes.

\section{Results}

Five major themes emerged from the qualitative interviews conducted with parent participants. The themes that emerged and were shared by both completers and noncompleters were 1) program content; 2) program materials; 3) program structure; and 4) endorsements. A theme focused on the barriers to participation emerged only for parents who were unable to complete the program. An overview of how themes align with the implementation outcomes of interest is displayed in Table 3.

\section{Program Content}

The majority of parents found the Pathways curriculum to be helpful in learning how to manage their children's problematic behaviors and enjoyed learning new parenting skills. Examples included concrete skills, such as strategies for working with their children, as well as a change in perspective about their parenting. Some parents mentioned the ease of learning new disciplinary methods and appreciated having alternatives. One parent stated

It's just a different way of disciplining your children without physically harming them... we got our butt whooped, that's what we was brought up to do. It's more than one way...There's other ways around [physical punishment] and the program was actually one of them [Participant 142, completer].

It is important to note that three parents stated that they did not find the new techniques to be useful with their children. For example, one parent believed that the new disciplinary methods presented were not a good fit for her child because her family was experiencing problems (e.g., suicidal threats from child, bullying, maternal depressive symptoms) that were outside the scope of the Pathways curriculum. The other parents $(n=2)$ believed their children exhibited severe child emotional problems, and as a result, the techniques were not as effective and the children were not responsive to the new skills demonstrated by their parents. Despite this lack of perceived fit by a small number of parents, some of these parents spoke highly of the program and believed it would be helpful for families with less severe child emotional and family problems, as well as those in need of more introductory 
parenting skills, such as getting their child dressed in the morning and ignoring minor child misbehavior.

Building Positive Parent-Child Relationships-Parents identified the strategies for building positive relationships with their children as a specific component in the Pathways curriculum that they found useful. Many parents discussed their satisfaction with the curriculum activities that focused on improving their communication skills, use of positive reinforcement, and frequency of quality time spent with their children. One parent discussed the ways in which she found the program to be enlightening:

...all the strategies and ways to cope with your kids and you know, doing special activities, having good parental guidelines and plans and having more family fun night or something like that or a family outing, you know, anything that was educational. It reminded me to constantly encourage good behavior and to also basically interact with the child and... the program basically showed me how to do that [Participant 142, completer].

Improved stress and anger management techniques-Parents also discussed their appreciation for learning how to manage their stress and anger, which many described as a significant problem. Issues with anger and stress were negatively impacting the home environment and parents interviewed believed Pathways presented strategies to help them cope with problematic situations. One parent stated, "I'm glad they talked about anger management because we both have... high stress level, I guess... but we've learned how to breathe it through a little bit better" [Participant 111, completer]. Of the twenty-six parents who identified stress or anger as issues, no one mentioned Pathways being unsuccessful in helping them identify more effective management strategies.

\section{Program Materials}

The extent to which parents believed materials were useful, particularly the workbooks, emerged from participant interviews. Most parents believed the workbooks contained useful information about parenting strategies and techniques and continued to use them as a resource after completing the intervention. Reflective of the mostly positive feedback, one parent stated:

I still pick them up and read them, like once a week I'll flip through them. I love them. I absolutely love them. And I like that we get to keep them because no matter the program's over, you still got the workbooks there to pick up [Participant 137, completer].

Not all parents, however, viewed the materials favorably. A few parents commented on the lack of relevance of the workbook examples in their daily lives. One parent discussed issues practicing some of the parent-child bonding activities suggested in the workbook:

Like the examples... was just, like, ridiculous...they weren't activities that [our family would] do together. I just didn't like being forced to do activities I knew I wouldn't be doing, like, we wouldn't be playing no card games or nothing like 
that...not when [my child] got homework or other stuff to do [Participant 106, completer].

Another parent believed that the workbook should be "more descriptive to where other [families] can understand it" [Participant 103, non-completer]. Additionally, suggestions were made about updating the questions and examples in the workbook to reflect family functioning specific to the United States.

Related to the program videos, three parents commented on issues pertaining to satisfaction and fit. The videos were produced in Australia and parents who mentioned their dissatisfaction with the video had difficulty understanding the Australian accent and expressions.

I didn't like how fast they [talked] and I didn't understand half of the things they said. [Practitioner's Name] would have to pause it and ...explain it to me... what they were saying. [The narrator in the video] was Australian...I could not understand him. Some things I just couldn't understand [Participant 100, noncompleter].

Another parent stated:

Some of the terminology [in the video], you could tell was UK or Australian, just in the terms they used, and more of the British Australian attitude towards things... It just doesn't apply as well in America. [In the video], I seem to recall the term "flat" being used, and there were certain words that were foreign in America... most people would have no idea what they're talking about. Things like that...just the terminology and the personalities are different [Participant 154, completer].

Similar to the workbooks, parents suggested that the videos be adapted to address the parenting needs specific to families in the United States. Despite a few comments pertaining to issues understanding Australian accents and terminology, generally the videos did not seem to be a significant barrier to parents' overall perceptions of Pathways.

\section{Program Structure}

Convenient Treatment Modality-Parents also mentioned that conducting the intervention in the home made the learning process more useful because parents were able to apply the new skills in a setting most familiar to the family. A parent stated:

It was just easier for her to come into my environment and see how my environment is so she can get a feel for what's going on. I thought it was set up really well. You guys come out here so it's comfortable for me and it's natural for [my child] in a natural environment [Participant 106, completer].

Conducting sessions in the home also allowed for in-depth discussion of parenting issues and opportunities for more parent practice and individualized feedback from the practitioner. One parent explicitly compared Pathways to other parenting programs that she had completed, and felt that the individual attention was more helpful because it was customized for her family's needs. 
Substantial or Burdensome Time Commitment-Completers and non-completers commented on the time commitment required to participate in the program. This included issues pertaining to: the availability of sessions during evenings and weekends; fitting in a session each week; the length of individual sessions, some of which ran as long as two hours; and the fourteen session commitment. Parents acknowledged that participating in Pathways required efforts to "fit" the program into their family's daily schedule which, at times, could be problematic:

It's almost too much to have an appointment on top of everything else every week. I would do it differently like every other week or so, something like that...the meetings are just...there's too many in that short period of time. That's what I would change [Participant 129, non-completer].

Parents also commented on the time commitment involved with preparing for and participating in weekly sessions. For example, a few parents struggled with the volume of reading required in order to complete the homework, as well as the volume of information that Pathways presented during the 14-week intervention. In fact, one parent believed that there was so much information given to her on strategies to effectively discipline her children that she found it difficult to apply everything she had learned when needed. Additionally, this parent suggested that Pathways tailor training so that the strategies offered directly relate to the parenting/child behavior issues communicated by the parent.

\section{Endorsements}

Parents consistently recommended the program and thought that other parents would benefit from participating in it. They expressed that the program had helped them and thought that other parents should know that it was helpful. It is important to note that despite participants' initial skepticism, the majority of parents found Pathways to be effective and encouraged more parents to participate in the program. For example, one caregiver offered advice for reluctant participants:

I would tell [other parents] to really be attentive. I think at the beginning I wasn't really that attentive. I was not open to the idea of somebody telling me how to raise my kids, but I would tell them to be open to it....I would tell them "You'll be surprised at some of the things that might be effective" [Participant 143, completer].

Many of the parents who were unable to complete the program also commented on their satisfaction with the program. For example, a parent who completed less than six sessions stated, "I think it would've taught me better ways for me to do things with my kids. I kind of regret it and I kind of resent myself that I didn't complete it" [Participant 108, noncompleter]. Participants identified the need for this program to be available to other members of the community. Some parents tried to refer people they knew to the program and others just stated that they thought parents would benefit from the Pathways program. Several parents revealed that they shared Pathways strategies and materials with other parents. 


\section{Barriers to Participation}

Overwhelming Circumstances and Competing Commitments-A recurrent theme across non-completer interviews was the presence of obstacles significantly reducing parents' ability to participate in Pathways. In fact, parents in the non-completer group reported having to constantly cancel or reschedule sessions with their practitioner due to a variety of circumstances including medical emergencies, parents gaining new employment, domestic disputes, and conflicting appointments with court-ordered services. Parents consistently stressed the need to secure and maintain employment. Meeting their families' basic needs for housing and income took priority over participating in the Pathways program.

I had been legally evicted when we was right in the middle of the program, me and [practitioner]. And me and my kids were, well they were staying with my brother, then with my mom for three weeks and I was sleeping in my car. I just had so much going on... it's like I got too much on my plate right now for the program [Participant 122, non-completer].

When discussing the competing demands on her time, another mother stated

...I had like five different [child welfare services people come into my house....and going to court...plus I'm going through my own family matters.... My mom, she has lung cancer, [chronic obstructive pulmonary disease], emphysema, sleep apnea, and she on $12 \%$ oxygen...so, my mom, and my kids, and my financial [struggles] ...I mean, just a lot of daily stress [Participant 130, non-completer].

Other parents corroborated this sentiment and believed the demands of system involvement in order to close their child welfare case (e.g., court-ordered appointments, psychological assessments, random drug screens) contributed to their inability to complete the program. It is also important to note that some of the barriers were related to parents' efforts to create opportunities that would assist them in meeting the needs of their children, such as attending college to obtain a post-secondary degree.

I was going to court every week and I was seeing my kids at three different places every week and I had trouble with my van and I actually ended up getting stuck up in the city, couldn't get back here, things like that. Basically a lot of things had changed around here...just pretty much adjusting to different things...I actually started school a couple of months ago and that's been difficult to work around...I just really haven't had a whole lot of time...it's hard to schedule things and then be able to keep them, not knowing what's gonna happen with the kids and what not [Participant 110, non-completer].

\section{Discussion}

Our study examined the acceptability and appropriateness of Pathways among parents involved in the child welfare system. Parents' perceptions of the program were explored to identify intervention characteristics that pointed to program fit and satisfaction. This study found that the majority of parents considered Pathways' curriculum and materials to be useful in helping them improve problematic child behavior by utilizing alternative discipline 
strategies rather than corporal punishment. Parents believed the program provided them with new methods to interact with their child, and continued to use program materials (e.g., books) outside of sessions and after completing the program. This suggests that Pathways' curriculum is applicable to parents who are involved in the child welfare system and provides tools that reinforce positive parenting behaviors. It was important to complete several sessions to receive some benefit from the program; the few parents who did not find the program satisfactory were those who had participated in fewer than 4 sessions.

Consistent with the Conceptual Model of Implementation Research (Proctor et al., 2009), as well as previous studies on the barriers to treatment effectiveness for at-risk families (Kazdin \& Wassell, 2000; Kruzich et al., 2014), our study findings suggest attendance and adherence to program components contribute to participants' perception of program acceptability.

Despite the general satisfaction with program content and materials, and the enthusiastic endorsement of the program to other parents, the overwhelming number of problems parents faced on a daily basis was evident in our study (e.g., job loss, medical emergencies, and residence evictions). These challenges made it nearly impossible for many parents to consistently attend weekly Pathways sessions. The majority of non-completers discussed these stressors as barriers that affected their ability to participate in Pathways. Our findings suggest, in order for evidence-based parenting programs to be most appropriate and beneficial, services must be offered that address any basic needs for shelter, income, and healthcare prior to or concurrent with parenting programs. This speaks to the need for more comprehensive assessments and services for parents involved in the child welfare system. The time commitment required to participate in Pathways was discussed, in detail, by parents. And while sometimes burdensome, the time commitment was not a barrier to program completion for most parents.

It is important to note how often parents mentioned that the barriers to participation involved requirements for other services. Examples of these commitments include required court hearings, visiting children who were removed from the home, or attending employment assistance programs. Families involved in the child welfare system frequently experience numerous stressors including competing demands within their child welfare case plan.

Although these examples are just a few possibilities, they illustrate the complicated nature of engaging child welfare clients in behavioral parent training programs (Author, XXXX; McWey, Holtrop, Wojciak, \& Claridge, 2015). Juggling multiple competing demands from child welfare greatly reduced the time participants had available to attend Pathways sessions. This highlights a need for a more coordinated approach to addressing families' basic needs (e.g., stabilizing employment and housing needs), and then continuing with services that address psychosocial and parenting needs (Marsh, Smith, \& Bruni, 2011; Saldana, 2015; Traube, He, Zhu, Scalise, \& Richardson, 2015). Despite these numerous competing demands, $70 \%$ of the sample completed ten or more Pathways sessions (omitted for blind review).

\section{Study Limitations}

This study should be interpreted in light of two potential limitations. First, the parent interviews chosen for the analysis consisted entirely of females. Fathers are often excluded 
from parenting research (Pleck, 2012), which is problematic because they may have a different perspective on behavioral parent training programs. Father perspectives on Pathways is not captured in this study. As a result, it is not clear if fathers would share the same perceptions of the program's acceptability and appropriateness. Second, no strategies were conducted to assess credibility. Credibility, a type of criteria commonly used to assess rigor in qualitative studies, involves ensuring that the data analyzed adequately represents the views of the participants (Guba, 1981). Strategies to establish credibility, such as member checking or triangulation, were not conducted in our analysis. Therefore, there is no way to determine if the themes presented in this study adequately represent the parent perspective. Despite the absence of strategies to ensure creditability, this study did incorporate strategies to address other types of criteria for rigor (e.g., transferability, confirmability, reliability).

Pathways has yet to be explored extensively among child welfare involved families in the United States (Author, XXXX). The research findings in this study provide the most compelling evidence, to date, that parents involved in the child welfare system find Pathways to be both acceptable and appropriate. Key aspects of acceptability included the home visiting model, program materials, and delivery of the content. Additionally, the majority of parents believed the program content met their needs and they were able to apply program components to help manage child behavioral problems (e.g., appropriateness). While barriers to participation are also evident, their overall favorable reaction suggests that Pathways is a promising program for child welfare involved families.

Implementation outcomes have been conceptually and theoretically linked to treatment outcomes (Proctor et al., 2009); therefore, understanding outcomes related to program satisfaction and perceived relevance is a vital step in increasing the uptake of an EBI by child welfare agencies as a strategy to improve child and family outcomes. Acceptability and appropriateness of a program may increase parent engagement in the services provided by the child welfare service sector. This suggests that an EBI that parents view favorably, such as Pathways, may be well situated for adoption by child welfare agencies in the US. However, additional research is needed to develop and test specific implementation strategies that decrease the barriers and increase the facilitators to program participation and, ultimately, program effectiveness for families involved in the child welfare system.

\section{References}

Ammerman, RT. Methodological issues in child abuse and neglect research. In: Lutzker, JR., editor. Handbook of child abuse research and treatment. New York: Plenum; 1998. p. 117-132.

Barth RP. Preventing child abuse and neglect with parent training: Evidence and opportunities. Future of Children. 2009; 19(2):95-118. [PubMed: 19719024]

Bodenmann G, Cina A, Ledermann T, Sanders MR. The efficacy of the Triple P-Positive Parenting Program in improving parenting and child behavior: A comparison with two other treatment conditions. Behaviour Research and Therapy. 2008; 46(4):411-427. [PubMed: 18313033]

Chaffin M, Bonner BL, Hill RF. Family preservation and family support programs: Child outcomes across client risk levels and program types. Child Abuse \& Neglect. 2001; 25:1269-1289. [PubMed: 11720379] 
Chaffin M, Hecht D, Bard D, Silovsky JF, Beasley WH. A statewide trial of the SafeCare home-based services model with parents in Child Protective Services. Pediatrics. 2012; 129:509-515. [PubMed: 22351883]

De Graff I, Speetjens P, Smit F, De Wolff M, Tavecchio L. Effectiveness of the Triple P Positive Parenting Program on parenting: A meta-analysis. Fam Relat. 2008; 57:553-566.

DePanfilis D, Dubowitz H. Family connections: A program for preventing child neglect. Child Maltreatment. 2005; 10:108-123. [PubMed: 15798007]

Eyeberg SM, Ross AW. Assessment of child behavior problems: The validation of a new inventory. Journal of Clinical Child Psychology. 1978; 7:113-116.

Gershater-Molko RM, Lutzker JR, Wesch D. Project SafeCare: Improving health, safety, and parenting skills in families reported for, and at-risk for child maltreatment. Journal of Family Violence. 2003; 18:377-386.

Guba EG. Criteria for assessing the trustworthiness of naturalistic inquiries. Educational Resources Information Center Annual Review Paper. 1981; 29:75-91.

Hansen DJ, Warner JE. Treatment adherence of maltreating families: A survey of professionals regarding prevalence and enhancement strategies. Journal of Family Violence. 1994; 9:1-19.

Kazdin AE, Wassell G. Predictors of barriers to treatment and therapeutic change in outpatient therapy for antisocial children and their families. Mental Health Services Research. 2000; 2:27-40. [PubMed: 11254067]

Kessler RC, Chiu WT, Demler O, Walters EE. Prevalence, severity, and comorbidity of twelve-month DSM-IV disorders in the National Comorbidity Survey Replication (NCS-R). Archives of General Psychiatry. 2005; 62:617-627. [PubMed: 15939839]

Kruzich JM, Jivanjee P, Robinson A, Friesen BJ. Family parents' perceptions of barriers to and supports of participation in their children's out-of-home treatment. Psychiatric Services. 2014; 54:1513-1518.

Lundahl BW, Tollefson D, Risser H, Lovejoy MC. A meta-analysis of father involvement in parent training. Research on Social Work Practice. 2008; 18:97-106.

Lundquist, LM.; Hansen, DJ. Enhancing treatment adherence, social validity, and generalization of parent-training interventions with physically abusive and neglectful families. In: Lutzker, JR., editor. Handbook of child abuse research and treatment. US: Springer; 1998. p. 449-471.

Marsh JC, Smith BD, Bruni M. Integrated substance abuse and child welfare services for women: A progress review. Children and Youth Services Review. 2011; 33:466-472. [PubMed: 21499525]

McWey LM, Holtrop K, Wojciak AS, Claridge AM. Retention in a parenting intervention among parents involved with the child welfare system. Journal of Child and Family Studies. 2015; 24(4): 1073-1087.

Miles, MB.; Huberman, AM. Qualitative data analysis: An expanded sourcebook. Sage; 1994.

Murray J, Farrington DP. Risk factors for conduct disorder and delinquency: Key findings from longitudinal studies. Canadian Journal of Psychiatry. 2010; 55:633-642. [PubMed: 20964942]

Nowak C, Heinrichs N. A comprehensive meta-analysis of Triple P - Positive Parenting Program using hierarchical linear modeling: Effectiveness and moderating variables. Clinical Child and Family Psychology Review. 2008; 11:114-144. [PubMed: 18509758]

NVivo 10 [software program]. QSR International. 2012 http://www.qsrinternational.com/ products_nvivo.aspx.

Pleck JH. Integrating father involvement in parenting research. Parenting. 2012; 12:243-253.

Pope C, Ziebland S, Mays N. Analysing qualitative data. British Medical Journal. 2000; 320(7227): 114-116. [PubMed: 10625273]

Prinz RJ, Sanders MR, Shapiro CJ, Whitaker DJ, Lutzker JR. Population-based prevention of child maltreatment: The US Triple P system population trial. Prevention Science. 2009; 10(1):1-12. [PubMed: 19160053]

Proctor EK, Landsverk J, Aarons G, Chambers D, Glisson C, Mittman B. Implementation research in mental health services: An emerging science with conceptual, methodological, and training challenges. Administration and Policy in Mental Health and Mental Health Services Research. 2009; 36:24-34. [PubMed: 19104929] 
Proctor E, Silmere H, Raghavan R, Hovmand P, Aarons G, Bunger A, Hensley M. Outcomes for implementation research: Conceptual distinctions, measurement challenges, and research agenda. Administration and Policy in Mental Health and Mental Health Services Research. 2011; 38(2): 65-76. [PubMed: 20957426]

Ritchie, J.; Lewis, J., editors. Qualitative Research Practice: A Guide for Social Science Students and Researchers. SAGE; 2003.

Saldana L. An integrated intervention to address the comorbid needs of families referred to child welfare for substance use disorders and child neglect: FAIR pilot outcomes. Child Welfare. 2015; 94(4)

Sanders MR, Markie-Dadds C, Tully LA, Bor W. The triple P-positive parenting program: A comparison of enhanced, standard, and self-directed behavioral family intervention for parents of children with early onset conduct problems. Journal of Consulting and Clinical Psychology. 2000; 68:624-640. [PubMed: 10965638]

Sanders, MR.; Markie-Dadds, C.; Turner, KM. Theoretical, scientific and clinical foundations of the Triple P-Positive Parenting Program: A population approach to the promotion of parenting competence. Vol. 1. Queensland: Parenting and Family Support Centre, The University of Queensland; 2003.

Sanders, MR.; Pidgeon, AM. Practitioner's manual for Pathways Triple P. Brisbane, QLD, Australia: Triple P International; 2005.

Staudt M. Treatment engagement with parents of at-risk children: Gaps in research and conceptualization. Journal of Child and Family Studies. 2007; 16:183-196.

Traube DE, He AS, Zhu L, Scalise C, Richardson T. Predictors of substance abuse assessment and treatment completion for parents involved with child welfare: One state's experience in matching across systems. Child Welfare. 2015; 94(4)

Turner KM, Sanders MR. Help when it's needed first: A controlled evaluation of brief, preventive behavioral family intervention in a primary care setting. Behavior Therapy. 2006; 37(2):131-142. [PubMed: 16942967]

Williams JH, Van Dorn RA, Bright CL, Jonson-Reid M, Nebbitt VE. Child maltreatment and. delinquency onset among African American adolescent males. Research on Social Work Practice. 2010; 20:253-259. [PubMed: 23730121]

Wiggins TL, Sofronoff K, Sanders MR. Pathways Triple P- Positive Parenting Program: Effects on parent-child relationships and child behavior problems. Family Process. 2009; 48:517-530.

[PubMed: 19930436] 


\section{Table 1}

\section{Summary of Pathways Program Content}

\begin{tabular}{|c|c|c|}
\hline Session Number & Content & \\
\hline 1. Intake Interview & $\begin{array}{l} \\
\cdot \\
\cdot \\
\cdot \\
\cdot \\
\cdot\end{array}$ & $\begin{array}{l}\text { Nature and history of presenting problem } \\
\text { Associated problems } \\
\text { Developmental, social, and relevant family history } \\
\text { Parent's perception of the problem } \\
\text { Keeping track of the children's behavior }\end{array}$ \\
\hline $\begin{array}{l}\text { 2. Observation and Sharing of Assessment } \\
\text { Findings }\end{array}$ & $\begin{array}{l} \\
\cdot \\
\cdot \\
\cdot \\
\cdot \\
.\end{array}$ & $\begin{array}{l}\text { Completion of intake interview/s } \\
\text { Observation of parent-child interaction } \\
\text { Review of assessments results } \\
\text { Causes of child behavior problems } \\
\text { Goals for change and intervention negotiation }\end{array}$ \\
\hline 3. Promoting Children's Development & $\begin{array}{l}\cdot \\
\cdot \\
\cdot \\
\cdot\end{array}$ & $\begin{array}{l}\text { Principles of positive parenting } \\
\text { Developing positive relationships with children } \\
\text { Encouraging desirable behavior } \\
\text { Teach new skills and behaviors }\end{array}$ \\
\hline 4. Managing Misbehavior & • & $\begin{array}{l}\text { Skills to manage misbehavior } \\
\text { Developing parenting routines } \\
\text { Finalizing behavior charts }\end{array}$ \\
\hline 5. Practice Session 1 & $\begin{array}{l}\cdot \\
\cdot \\
\cdot \\
\cdot \\
\cdot \\
.\end{array}$ & $\begin{array}{l}\text { Practice task } \\
\text { Self-evaluation and feedback } \\
\text { Goal Setting } \\
\text { Other issues } \\
\text { Goals for between-session practice }\end{array}$ \\
\hline 6. Parent Traps & $\cdot$ & Recognizing and understanding parent traps \\
\hline 7. Parent Traps & - & How to get out of parent traps \\
\hline 8. Practice Session 2 & $\begin{array}{l}\cdot \\
\cdot \\
\cdot \\
\cdot \\
\cdot\end{array}$ & $\begin{array}{l}\text { Practice task } \\
\text { Self-evaluation and feedback } \\
\text { Goal setting } \\
\text { Other issues } \\
\text { Goals for between-session practice }\end{array}$ \\
\hline 9. Practice Session 3 & $\begin{array}{l} \\
\cdot \\
\cdot \\
\cdot\end{array}$ & $\begin{array}{l}\text { Practice task } \\
\text { Self-evaluation and feedback } \\
\text { Goal setting } \\
\text { Other issues }\end{array}$ \\
\hline
\end{tabular}




\begin{tabular}{|c|c|c|}
\hline Session Number & Content & \\
\hline & $\bullet$ & Goals for between-session practice \\
\hline 10. Planned Activities Training & $\begin{array}{l}\cdot \\
\cdot \\
\cdot\end{array}$ & $\begin{array}{l}\text { Update on progress } \\
\text { High-risk situations } \\
\text { Planned activities routines }\end{array}$ \\
\hline 11. Using Planned Activities Training & $\begin{array}{l}\cdot \\
\cdot \\
\cdot \\
\cdot\end{array}$ & $\begin{array}{l}\text { Encouraging independent play } \\
\text { Further planning } \\
\text { Engaging activity } \\
\text { Getting ready to go out }\end{array}$ \\
\hline 12. Coping with Anger & • & $\begin{array}{l}\text { Recognizing and understanding anger and how it affects parenting } \\
\text { Communication styles } \\
\text { Self-calming and relaxation techniques }\end{array}$ \\
\hline 13. Managing Your Anger & • & $\begin{array}{l}\text { Coping statements } \\
\text { Challenging unhelpful thoughts } \\
\text { Coping plans for high risk situations }\end{array}$ \\
\hline 14. Program Close & $\begin{array}{l} \\
\cdot \\
\cdot \\
\cdot \\
\text { - } \\
\text { - }\end{array}$ & $\begin{array}{l}\text { Review use of positive parenting strategies } \\
\text { Phasing out the program } \\
\text { Identifying changes that have been made } \\
\text { Maintaining changes } \\
\text { Problem solving for the future }\end{array}$ \\
\hline
\end{tabular}




\section{Table 2}

\section{Interview Guide}

\begin{tabular}{|c|c|}
\hline Domain & Sample Question \\
\hline Positive experiences participating in Pathways & $\begin{array}{l}\text { What it was like for you to have }\langle\text { practitioner }>\text { come to } \\
\text { your home and work with you on the Pathways } \\
\text { materials? }\end{array}$ \\
\hline Negative experiences participating in Pathways & What was the worst part of participating in Pathways? \\
\hline Perceptions of change, parent and child & $\begin{array}{l}\text { Looking back, what were things like in your home } \\
\text { before you started Pathways and what is different now? }\end{array}$ \\
\hline Perceptions of materials (books and videos) & $\begin{array}{l}\text { Was there ever a time when you used the workbook } \\
\text { when }<\text { practitioner }>\text { wasn't there? }\end{array}$ \\
\hline Relationship with practitioner & What was your relationship with <practitioner $>$ like? \\
\hline Areas of improvement & $\begin{array}{l}\text { If you were to make one change to the program to make } \\
\text { it better for other people to use it, what would you } \\
\text { change? }\end{array}$ \\
\hline Barriers to participation (non-completers only) & $\begin{array}{l}\text { What was the most important factor that contributed to } \\
\text { your stopping the Pathways program? }\end{array}$ \\
\hline
\end{tabular}


Table 3

Themes and Associated Implementation Outcomes

\begin{tabular}{|c|c|c|c|}
\hline Major Themes & Sub-Themes & $\begin{array}{l}\text { Implementation } \\
\text { Outcome(s) }\end{array}$ & \\
\hline \multirow[t]{2}{*}{ Program Content } & Building positive parent-child relationships & • & Acceptability \\
\hline & Improved stress and anger management techniques & • & Appropriateness \\
\hline \multirow[t]{3}{*}{ Program Materials } & Workbooks & $\bullet$ & Acceptability \\
\hline & Activities & • & $\begin{array}{l}\text { Acceptability } \\
\text { Appropriateness }\end{array}$ \\
\hline & Videos & • & Appropriateness \\
\hline \multirow[t]{2}{*}{ Program Structure } & Convenient treatment modality & & $\begin{array}{l}\text { Acceptability } \\
\text { Appropriateness }\end{array}$ \\
\hline & Substantial or burdensome time commitment & • & Acceptability \\
\hline Endorsements & & - & Acceptability \\
\hline $\begin{array}{l}\text { Barriers to } \\
\text { Participation }\end{array}$ & $\begin{array}{c}\text { Overwhelming circumstances/Competing } \\
\text { commitments }\end{array}$ & • & Appropriateness \\
\hline
\end{tabular}

